\title{
COMPUTER MODELS IN ENVIRONMENTAL PLANNING
}




\title{
COMPUTER MODELS IN ENVIRONMENTAL PLANNING
}

\author{
Steven I. Gordon \\ Department of City and Regional Planning \\ The Ohio State University \\ Columbus, Ohio
}


Copyright $\odot 1985$ by Van Nostrand Reinhold Company Inc.

Softcover reprint of the hardcover 1st edition 1985

Library of Congress Catalog Card Number: 84-13031

ISBN-13: 978-1-4684-6592-1

All rights reserved. No part of this work covered by the copyright hereon may be reproduced or used in any form or by any means-graphic, electronic, or mechanical, including photocopying, recording, taping, or information storage and retrieval systems--without permission of the publisher.

Published by Van Nostrand Reinhold Company Inc.

135 West 50th Street

New York, New York 10020

Van Nostrand Reinhold Company Limited

Molly Millars Lane

Wokingham, Berkshire RG11 2PY, England

Van Nostrand Reinhold

480 Latrobe Street

Melbourne, Victoria 3000, Australia

Macmillan of Canada

Division of Gage Publishing Limited

164 Commander Boulevard

Agincourt, Ontario MIS, 3C7, Canada

$\begin{array}{lllllllllllllll}15 & 14 & 13 & 12 & 11 & 10 & 9 & 8 & 7 & 6 & 5 & 4 & 3 & 2 & 1\end{array}$

\section{Library of Congress Cataloging in Publication Data}

\section{Gordon, Steven I.}

Computer models in environmental planning.

Includes index.

1. Environmental policy-Mathematical models.

2. Environmental policy-Data processing. I. Title.

HC79.E5G655 $1984 \quad 363.7^{\prime} 0525^{\prime} 02854$

ISBN-13: 978-1-4684-6592-1 e-ISBN-13: 978-1-4684-6590-7

DOI: $10.1007 / 978-1-4684-6590-7$ 
To my parents, Jack and Rose Gordon; and to my family, Gaybrielle, Ben, and Tim-for their love and support. 


\section{Preface}

The purpose behind Computer Models in Environmental Planning is to provide a practical and applied guide to the use of these models in environmental planning and environmental impact analysis. Models concerning water quality, air quality, stormwater runoff, land capability evaluation/land information systems, and hazardous waste disposal are reviewed and critiqued. I have tried to emphasize the practical problems with data, computer capabilities, and other analytical questions that must be faced by the practitioner attempting to use these models. Thus, I do not delve too deeply into the theoretical underpinnings of the models, referring the reader instead to specialized references in this area. For each environmental area, I review the major models and methods, comparing their assumptions, ease of use, and other characteristics. Practical examples illustrate the benefits and problems of using each model.

Computer models are increasingly being used by planning and engineering professionals for locating and planning public works, and industrial, commercial, and residential projects, while evaluating their environmental impacts. The requirements of the National Environmental Policy Act and related state laws as well as separate state and federal laws concerning air and water quality, stormwater runoff, land use, and hazardous waste disposal have made the use of these methods mandatory in many circumstances. Yet, explanations of both the benefits and problems associated with supposedly easy-to-use computer versions of these models and methods remain, at best, difficult to retrieve and, at worst, incomplete.

A number of federal and state agencies have invested rather heavily in the development of computer models. In some instances, one can make the case that the investment has been wasted. The documentation may be impossible to decipher, if it exists at all, or there is no correlation between the documentation and the computer code. One does not wish to waste time trying to learn that this is the case. In many other cases, these problems do not occur. In fact, there are many 
computer models that are well documented, readily transportable to other systems, and of great use in answering the required environmental questions under state and federal laws and regulations. Unfortunately, the information on which models are available, how they can be acquired, and which are worth the investment in time, effort, and other resources is scattered among a wide array of government documents. This makes it quite difficult for those not intimately connected with the development of the models to acquire and use them.

To this end, I have tried to assemble in one place a comprehensive review of the major modelling efforts in the environmental planning arena. I hope it will help practitioners to incorporate such models into their work, and that it will help students of environmental modelling obtain a useful overview of the practical aspects of simulation modelling and impact analysis.

STEVEN I. Gordon 


\section{Acknowledgments}

Several people and organizations deserve recognition for their help in the production of this manuscript. First, I must thank Steven Arend, Scott Eberhart, Robert Johnson, and Bruce Riffle for their hard work in producing many of the illustrations used in the book. Second, Ellen Wallace and Madonna Alessandro must be credited with assisting with typing of much of the tabular and mathematical material in the original manuscript. Two organizations also deserve some recognition. The Ohio State University Task Force on Learning provided the original small grant that helped me to obtain and incorporate into my teaching and research efforts many of the computer models reviewed in this book. Finally, I must thank the W. K. Kellogg Foundation, who, through a National Fellowship, helped me to acquire some additional expertise in areas new to me and the IBM Personal Computer on which I composed most of the manuscript.

Any ideas and opinions are, of course, my own and should not be attributed to these individuals or organizations. 


\section{Contents}

Preface vii

Acknowledgments ix

1 Models in Environmental Planning 1

Introduction 1

Models and Decision Making 3

Organization of the Book 12

References 13

2 Water Quality Models 14

Introduction 14

Streeter-Phelps Models: Dissolved Oxygen in a River 17

A Statistical Approach to Dissolved Oxygen Modelling 25

Water Quality Models Embedded in Other Modelling Efforts 36

Examples: Making a Policy Decision 39

References 40

3 Stormwater Runoff Models $\mathbf{4 2}$

Introduction 42

Theoretical Considerations:

The Hydrologic Cycle 45

Model Descriptions 52

References 76

4 Air Pollution Models 78

Introduction 78

Theoretical Considerations 81

Principal Models 84

Computer Model Descriptions 89 
xii CONTENTS

Model Validation 104

Modelling Examples 105

References 114

\section{Land Capability Evaluation 116}

Introduction 116

A History of Capability Analysis 119

Automatic Garbage or Hightech Capability Analysis 129

Issues and Problems with Automated Land Capability

Classification 135

Model Reviews 142

References 150

6 Hazardous Wastes 152

Introduction 152

Intertwined Entry Paths for Hazardous Wastes 153

The Fate of Hazardous Wastes 156

Model Reviews 161

References 184

Appendices

A Technical Transfer Problems 189

Introduction 189

The Transfer of Computer Programs 189

B Classified Bibliography 195

Introduction 195

Models in Environmental Planning 196

Water Quality Models 197

Stormwater Runoff Models 201

Air Pollution Models 203

Land Capability Evaluation 207

Hazardous Waste Disposal 211

Index 219 


\section{COMPUTER MODELS IN ENVIRONMENTAL PLANNING}

